\title{
Article \\ Effectiveness of Conflict Resolution Methods in Air Traffic Management
}

\author{
Anrieta Dudoit ${ }^{1, *}$, Vytautas Rimša ${ }^{1}$, Marijonas Bogdevičius ${ }^{2}$ and Jacek Skorupski $^{3, *(D)}$ \\ 1 Department of Aviation Technologies, Vilnius Gediminas Technical University (VILNIUS TECH), \\ LT-10223 Vilnius, Lithuania; vytautas.rimsa@vilniustech.lt \\ 2 Department of Mobile Machinery and Railway Transport, Vilnius Gediminas Technical \\ University (VILNIUS TECH), LT-10223 Vilnius, Lithuania; marijonas.bogdevicius@vilniustech.lt \\ 3 Faculty of Transport, Warsaw University of Technology, 00-662 Warsaw, Poland \\ * Correspondence: anrieta.dudoit@vilniustech.lt (A.D.); jacek.skorupski@pw.edu.pl (J.S.)
}

check for

updates

Citation: Dudoit, A.; Rimša, V.;

Bogdevičius, M.; Skorupski, J. Effectiveness of Conflict Resolution Methods in Air Traffic Management. Aerospace 2022, 9, 112. https:// doi.org/10.3390/aerospace9020112

Academic Editors: Stelios K. Georgantzinos, Georgios I. Giannopoulos, Konstantinos Stamoulis and Stylianos Markolefas

Received: 10 January 2022

Accepted: 14 February 2022

Published: 19 February 2022

Publisher's Note: MDPI stays neutral with regard to jurisdictional claims in published maps and institutional affiliations.

Copyright: (C) 2022 by the authors. Licensee MDPI, Basel, Switzerland. This article is an open access article distributed under the terms and conditions of the Creative Commons Attribution (CC BY) license (https:// creativecommons.org/licenses/by/ $4.0 /)$.

\begin{abstract}
Aircraft fly en route under concurrent event situations (conflicting situations), which occur when they operate in the same airspace but are too close to each other in the same time frame. Hence, the safe horizontal distance between them is not less than the standard $5 \mathrm{~nm}$. Free route airspace is such a concept, where such concurrent events need to be resolved when the location and number of such event "hotspots" are random in comparison with fixed route (conventional) airspace. This paper proposes two approaches to solving the traffic conflict in the sector by performing horizontal resolution maneuvers. The first of them uses the Dubins trajectory, while the second one uses a three-fold change of heading (3HC) method (for two types of angles). Apart from maintaining safe separation, we compared them, taking as a criterion the extension of the flight path of aircraft involved in the conflict, as the length of the flight is the primary factor determining flight time/delays and the increase in fuel consumption and greenhouse gas emissions. There may be other algorithms depending on the different data that can be identified through further research.
\end{abstract}

Keywords: air traffic management; free route airspace; aircraft conflict resolution; resolution algorithms; Dubins trajectory; $3 \mathrm{HC}$ method

\section{Introduction}

The air navigation service provider, mainly air traffic control (ATC) services, is responsible for aircraft operations in controlled airspace. The key roles of ATC are determined by ICAO's established three goals to prevent aircraft collision, to provide an orderly and expeditious flow of air traffic [1]. Therefore, because of increased traffic demand and modifications in the ATM system (which requires a fundamental shift in cognitive processing from the air traffic controllers) and the contribution to the increase in safety, there is a rationale to analyze aircraft conflict detection and resolution methods and their effectiveness.

The excessive use of air transport leads to the need for further investments in airport expansion and ATM modernization. The current study was focused on the ATM problem with respect to new procedures, such as free route, in terms of safety and effectiveness. The study was triggered by and aligned with the following performance objectives set by EUROCONTROL and the European Commission: (1) to improve ATM safety whilst accommodating air traffic growth; (2) to increase ATM network efficiency; (3) to strengthen ATM's contribution to aviation security and to environmental objectives; (4) to match capacity and air transport growth [2].

First, despite the fact that during the COVID-19 pandemic the traffic intensity drastically decreased [3], the traffic amount before the pandemic and according to STATFOR forecasts is to be recovered in the near future [4]. The year 2020 review of the total impact of 
COVID-19 produced an effect on flights, airlines, aircraft, airports, European States, air navigation service providers (ANSPs), and on sustainability and disclosed there were: 56.2 billion losses for airlines, airports \& ANSPs; 1.7 billion fewer passengers; and 6.1 million fewer flights-55\% down on 2019 and 51\% of all aircraft grounded at year-end [5].

Second, the European airspace was/is significantly fragmented according to the national borders [6], and the ground fixed system became an obstacle to development since air routes could not be modified without relocating ground-based navigation equipment, which would have incurred considerable costs and time $[7,8]$. The EU, in one of its projects pillars, proposed other concepts of EU airspace to be more adjusted to traffic demands, such as free route airspace (FRA) in the frame of Functional Airspace Blocks (FAB) [5,9]. However, to further improve the aforementioned three ICAO objectives under such concepts, the need appeared to develop an algorithm that would help in conflict detection and resolution on a horizontal plane definitively with a longer look-ahead time. In this way, a move from the current largely reactive (conventional) form of ATC to a more pro-active (FRA concept) control could be facilitated $[10,11]$.

Third, the flight does not take place from gate to gate on the shortest/user preferred route available $[12,13]$ because an en route air traffic control system consists of, for the most part, a geographical network in which aircraft are allowed to fly only along fixed, but not 'free' routes, thus, the increasing demand for air transportation is expected to progressively bring the entire ATM system to an overloaded and congested state [14]. Airspace modernization could result in EUR 245 billion of additional gross domestic product (GDP) for Europe by 2035 [15].

The problems presented above resulted in the development of the concept of FRA [16-18], independent of the existing air network, in which the flight path depends on user preferences, i.e., creating flexibility which most often comes down to the flight on the shortest route-from the entry/starting point to the exit/endpoint of the designated FRA [19-22]. This solution has many advantages. On one hand, it reduces the cost of air carriers, emissions to the atmosphere, and, to some point, the workload of air traffic controllers. These benefits as shown by studies demonstrating reduced costs up to $3.8 \%$ and maximum potential emissions near 300 tons of $\mathrm{CO}_{2}$ and 1.4 tons per year. On the other hand, it allows for effective use of airspace [23]. Some current deployments of the free route in Europe demonstrated to save around 25,000 nm flight distance per day (between 2-3.5\% of flight distance) [16]. However, except for the economic impact, from a sustainable perspective, delays on flights can cause environmental damage due to excessive fuel consumption and gas emissions [24].

However, from a mathematical point of view, as FRA causes the former flow of air traffic, considered as arranged, to transform to disarranged, i.e., the distributed air traffic control system (DATCS) [25], this, in turn, has an impact on the capacity of the airspace, air traffic controllers' workload (cognitive processing, i.e., the traffic complexity is increased and controllers have a hard time detecting conflicts in advance since there are no more old "hotspots" to concentrate on), and timely conflict detection and safe and rational conflict resolution [7]. Such DATCS includes enhancements in communication, navigation, and surveillance (CNS), as well as improved conflict detection and resolution devices [21]. In this paper, two concepts of solving the air traffic conflict in the airspace by performing horizontal maneuvers were proposed. The first of them uses the Dubins trajectory, while the second one uses the 3HC method proposed by Dudoit and Skorupski [25]. We compared them, taking the extension of the flight path of aircraft involved in the conflict as a criterion, as the length of the flight is a primary factor determining the increase in costs, delays, and greenhouse gas emissions.

The focus of our research was on the development of a mathematical model, and it cannot be used directly in free route conflict resolution, as it does not include the limitations of free route air traffic. 
The issue of conflict detection and resolution has been presented in the scientific literature for a long time [26-30]. The free route concept is a part of international research programmes [31,32], such as SESAR and NextGen.

\subsection{Conflict Detection and Resolution through the Systems}

When a potential loss of separation of one against the other aircraft is predicted, such aircraft have to be re-routed by safe systems and reliable methods [33]. Loss of separation (LOS) between aircraft or a conflict occurs whenever specified separation minima between those aircraft are breached, i.e., when they move towards each other, and it is predicted that they will violate their protected zones related to standard horizontal separation (usually $5 \mathrm{~nm}$ ) and/or vertical separation (usually $1000 \mathrm{ft}$ ) $[19,20,34]$. The problem to be analyzed so as to assure specified separation between aircraft when both planes fly en route and a potential LOS at a specified time has been identified.

Current tools in air traffic control are not sufficient to support the advanced conflict detection that has arisen from the implementation of FRA [18]. The electronic surveillance systems normally involve a computer system and a human surveillance operator, who follow the dynamic display in order to perform the surveillance tasks [35]. Because of potential human failures and operational errors, virtual assistance systems have appeared in the cockpit and on the ground to provide tactical decisions support and alert potential aircraft conflicts [36]. The ATM conflict prediction tool's medium traffic conflict detection (MTCD) [37]; a separation assurance aid, such as the tactical controller tool (TCT); and the ground-based safety net short-term conflict detection alert (STCA) are of $20 \mathrm{~min}, 5-8 \mathrm{~min}$, and 2 min look-ahead time tools, respectively. MTCD facilitates a move from the current largely reactive (conventional) form of ATC to a more pro-active (having a look far ahead before a conflict) control. These systems are the supporting means in ATC and work so as to alert about an upcoming conflicting situation [38] when ATCOs are expected to assess the situation and take appropriate actions on time.

In order to assure safe separation and to avoid human errors, there is a need for automation in ATM systems [39]. In general, automation in ATM means operating equipment with minimal or reduced human intervention. Due to the need to handle tasks by machines and high traffic demand, the process of automation in ATMs is still ongoing.

Thanks to the DATCS concept, some or all safety ensuring tasks could be handed over to aircraft operational systems. In the frame of this concept, it is important to choose the right conflict detection and resolution (CD\&R) algorithm, allowing precise automation of this process. Of course, all these functions must be supported by the appropriate computer systems. To adapt proposed conflict resolution methods to automation and application in DATCS, it is necessary to specify some of its parameters. It is very important to analyze the impact of uncertainties $[40,41]$ as due to surveillance systems, aircraft position, or its movement characteristics, and pilot errors affect the change of these parameters [25,30]. According to various/multiple surveillance sources (PSR, SSR, ADS-B, WAM, etc.) [36,42] based on the aircraft data used and provided to air traffic controllers' situational display/Human Machine Interface (HMI), the recommended latency of such an update is $6 \mathrm{~s}$, but in real performance, it is around $4 \mathrm{~s}$ which slightly affects the real-time positions of aircraft (during a $4 \mathrm{~s}$ time interval, an aircraft travels approximately $0.029 \mathrm{~nm}$ ). Communication transfer to pilots, and pilot reaction time and maneuver time, takes around $10 \mathrm{~s}$ which is approximately $0.075 \mathrm{~nm}$ aircraft flying time. To sum up, the whole process from the update blip to the pilot maneuver takes around $14 \mathrm{~s}$ which is approximately $1 \mathrm{~nm}$ aircraft flying time. The above-mentioned considerations should be taken into consideration, however, that is beyond the scope of this particular analysis.

\subsection{FRA Impact on Fuel Consumption and Emissions}

With a modernized airspace, the benefits are predicted to increase through the rest of the economy and create more positive outcomes [43]. 
Airspace modernization is necessary due to a fragmented European airspace, which means flights are 3\% longer than they could be. On the other hand, the modernized airspace produces bottlenecks that cause 10 min delays per flight and the longer routes mean more fuel burnt. A modernized airspace produces: (1) higher capacity with more efficient air navigation; (2) average flight times will be reduced 4 to 8 min per one-way flight; (3) average delays will decrease from 12 to $8 \mathrm{~min}$; and (4) lower carbon dioxide emissions per flight [16].

\subsection{Concept of the Study}

In general conflict resolution, algorithms use maneuvers to resolve aircraft conflicts on a vertical plane. However, this is not the most appropriate and rational way. In the changing ATM environment, the aircraft flying according to the algorithm when solving the conflict on a vertical plane can generate forthcoming secondary conflicts with other aircraft flying in close proximity [44]. Therefore, there is a need to find other possible safe and rational ways for how aircraft conflicts can be solved-which may be aircraft conflict solving on a horizontal plane. The advantage of such an algorithm is the ability to solve aircraft conflict by creating a set of possible actions, and at the same time not generating new conflicts with nearby aircraft. On the other side, alongside this advantage, there appears the so-called disadvantage that demands a reasonable time amount to manage this conflict detection and resolution so as to assure enough time to detect the conflict, choose the most appropriate resolution action, perform it and return to the flight planned trajectory.

Following the current trends, ATMs should accept safety as a constraint, not as the goal of action [45]. Because the analysis of horizontal resolution algorithms is of high interest for free route airspace, the analysis of the sensitivity of such a type of conflict resolution is one of the aims of this study. Moreso, a conflict resolution algorithm among solutions using horizontal maneuvers was analyzed in this paper, and as a result, two concepts were proposed. The first uses the Dubins trajectories for an angle of $3^{\circ}$ and $90^{\circ}$ between flight paths, while the second one uses straight flight with a three-fold change of heading $(3 \mathrm{HC})$ for the same angles among flight paths. The solutions in terms of safety and the necessary extension of the flight route as a determinant of time/delays and fuel consumption resulting in emissions into the environment were compared.

As was mentioned before, we focused on the mathematical model only. However, it could be applied in free route airspace conflict resolution, after including the characteristics of the aircraft's performances and airspace design.

\section{Conflict Resolution Algorithms}

The FRA concept assumes that all airspace users will plan their routes freely. The consequence of this will be an increase in the number of intersection points of the flight trajectory. We should expect that with such a 'free' organization, with a larger volume of traffic, the number of potential conflict "hotspots" would also increase. Thus, the choice of a conflict resolution algorithm can be crucial for the cost-effectiveness of FRA airspace users, airspace capacity, or the volume of emissions to the atmosphere.

In this paper, we propose to consider two algorithms for resolving conflict situations. The first one assumes that aircraft fly according to the Dubins trajectory; the second one assumes straight-line flight (3HC method). Of the many possible spatial configurations of aircraft involved in a conflict situation, we will analyze the most dangerous case when their distance from the intersection point and flight speed are such that the time of appearance at the collision point is the same. This situation is schematically presented in Figure 1. 


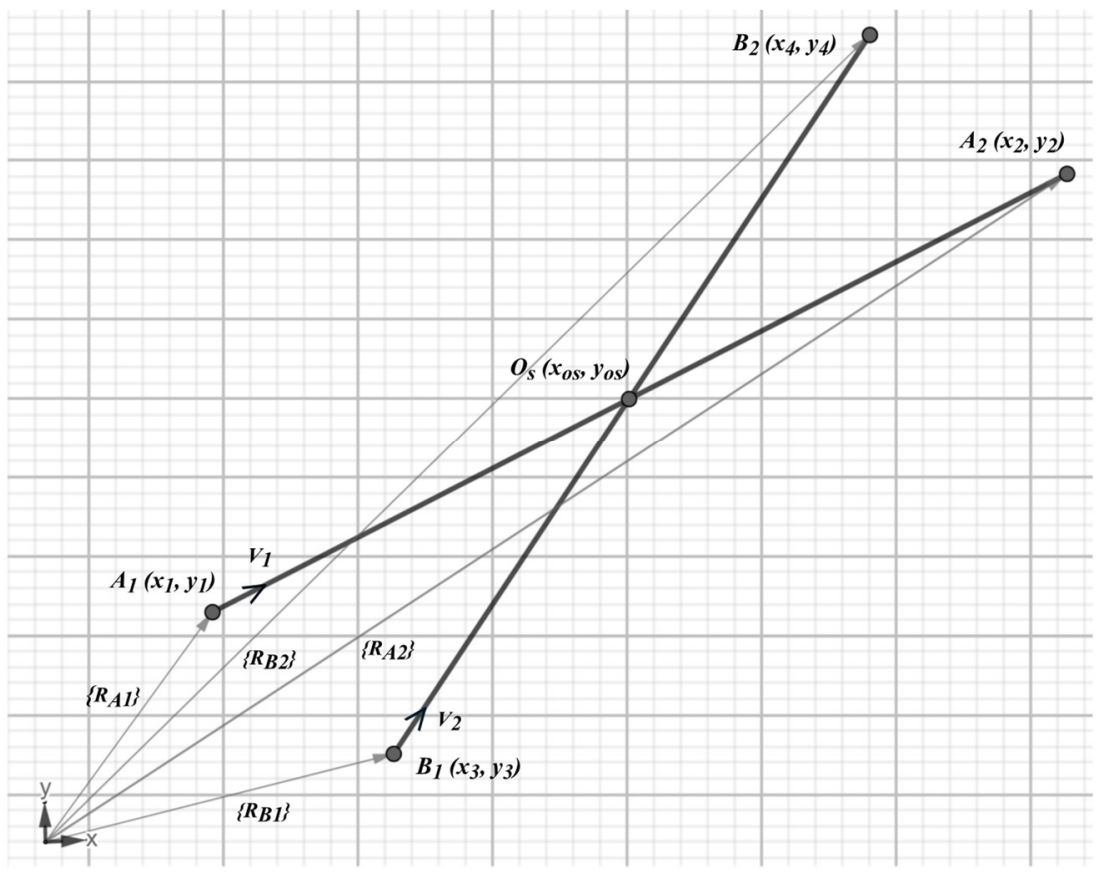

Figure 1. Example of a conflict situation.

An example of a conflict situation can be described as follows.

1. In the beginning, one aircraft (marked $\mathrm{A}$ ) is in point $A_{1}$ with coordinates $\left(x_{1}, y_{1}, z\right)$. while the other aircraft (marked $B$ ) is in point $B_{1}$ with coordinates $\left(x_{3}, y_{3}, z\right)$.

2. Destination points, respectively $A_{2}\left(x_{2}, y_{2}, z\right)$ and $B_{2}\left(x_{4}, y_{4}, z\right)$, determine the flight direction of aircraft.

3. We assume that both aircraft are in the same control sector and that a minimum separation of $5 \mathrm{~nm}$ applies in the examined airspace.

4. We analyze the problem in two dimensions as we assume that the aircraft fly at the same flight level, which means that a vertical separation of $1000 \mathrm{ft}$ does not apply. Therefore, in further calculations, we will omit the vertical coordinate $z$.

We will represent the starting and endpoints of both aircraft through vectors $\boldsymbol{R}_{A_{1}}, \boldsymbol{R}_{A_{2}}$, $\boldsymbol{R}_{B_{1}}$ and $\boldsymbol{R}_{B_{2}}$. The trajectories of both aircraft will be denoted by:

$$
\begin{gathered}
\boldsymbol{T}_{A}=\boldsymbol{R}_{A_{1}, A_{2}}=\boldsymbol{R}_{A_{2}}-\boldsymbol{R}_{A_{1}} \\
\boldsymbol{T}_{B}=\boldsymbol{R}_{B_{1}, B_{2}}=\boldsymbol{R}_{B_{2}}-\boldsymbol{R}_{B_{1}}
\end{gathered}
$$

where:

$$
\boldsymbol{R}_{A_{1}}^{\mathrm{T}}=\left[x_{1}, y_{1}\right], \boldsymbol{R}_{A_{2}}^{\mathrm{T}}=\left[x_{2}, y_{2}\right], \boldsymbol{R}_{B_{1}}^{\mathrm{T}}=\left[x_{3}, y_{3}\right], \boldsymbol{R}_{B_{2}}^{\mathrm{T}}=\left[x_{4}, y_{4}\right]
$$

The coordinates of the point $O_{s}$, where the trajectories $T_{A}$ and $T_{B}$ intersect are defined as follows [46]:

$$
\boldsymbol{R}_{O_{\mathrm{s}}}=\left[\begin{array}{c}
\frac{\left(x_{1} y_{2}-y_{1} x_{2}\right)\left(x_{3}-x_{4}\right)-\left(x_{1}-x_{2}\right)\left(x_{3} y_{4}-y_{3} x_{4}\right)}{\left(x_{1}-x_{2}\right)\left(y_{3}-y_{4}\right)-\left(y_{1}-y_{2}\right)\left(x_{3}-x_{4}\right)} \\
\frac{\left(x_{1} y_{2}-y_{1} x_{2}\right)\left(y_{3}-y_{4}\right)-\left(y_{1}-y_{2}\right)\left(x_{3} y_{4}-y_{3} x_{4}\right)}{\left(x_{1}-x_{2}\right)\left(y_{3}-y_{4}\right)-\left(y_{1}-y_{2}\right)\left(x_{3}-x_{4}\right)}
\end{array}\right]
$$

The coordinates of the point $O_{S}$, where the trajectories $T_{A}$ and $T_{B}$ intersect are one of the primary/fundamental data used for the analysis of our proposed two approaches of conflict resolution algorithms using horizontal maneuvers.

\subsection{Dubins Trajectory Method}

In geometry, the Dubins trajectory is the shortest curve, which connects two points in the 2D Euclidean plane with the initial and final points and directions specified, or with prescribed initial and terminal tangents to the path $[47,48]$. The Dubins trajectory 
consists of curves and line segments. The Dubins trajectories are used in the field of robotics and control theory as a way to plan paths for wheeled robots, airplanes, and underwater vehicles $[30,33]$.

The method of conflict resolution we propose involves changing the flight path of aircraft A, while aircraft B moves according to the initially planned trajectory (Figure 2).

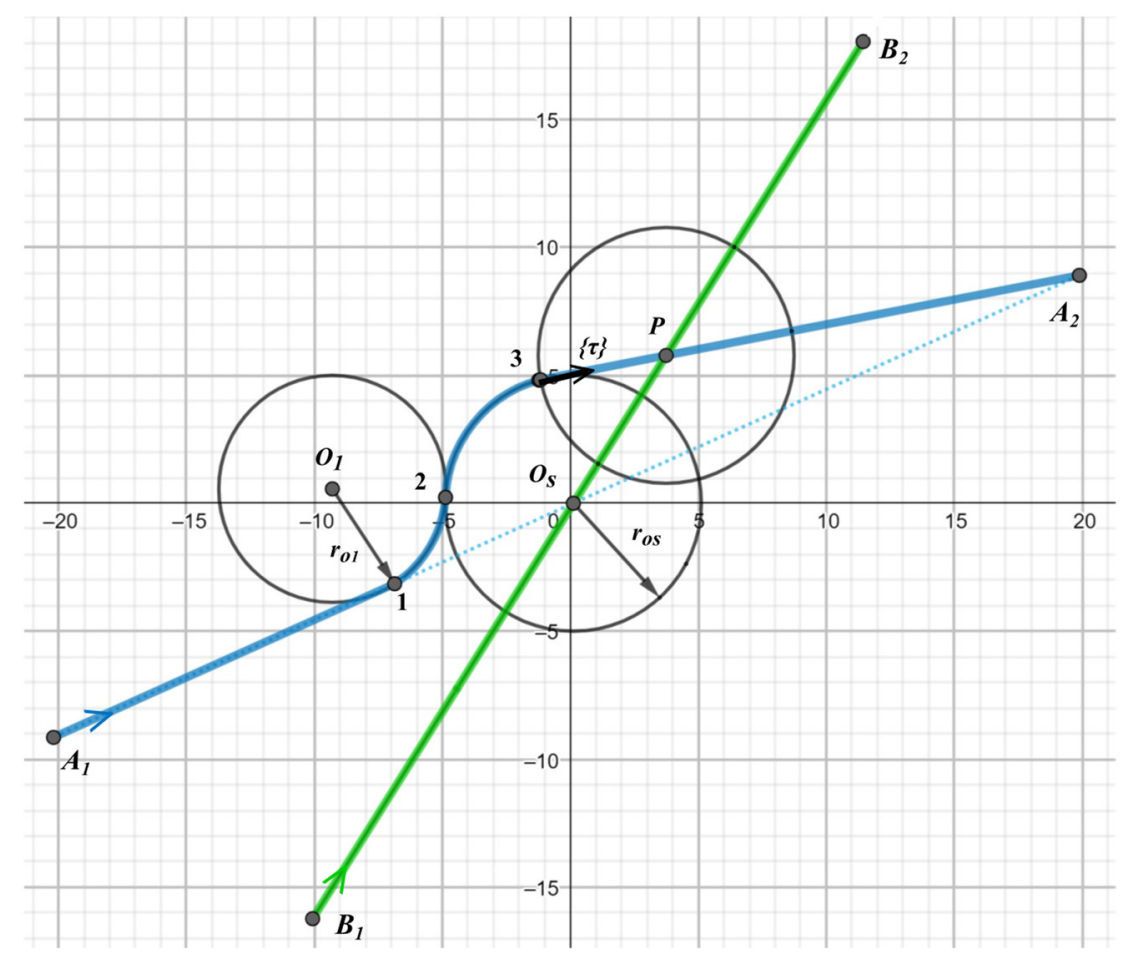

Figure 2. Conflict resolution based on the Dubins concept.

To determine the Dubins trajectory for aircraft $\mathrm{A}$, we use circles $O_{1}$ and $O_{S}$ with radii, respectively, $r_{O_{1}}$ and $r_{O_{S}}$. Considering that the movement of aircraft $\mathrm{A}$ takes place along the perimeter of the circle $O_{S}$, and the movement of aircraft $\mathrm{B}$ through its center, and taking into account the minimum separation used, it was assumed that $r_{O_{S}}=5 \mathrm{~nm}$. The optimization method presented in Section 2.3 ensures that primary conflict at point $O_{S}$ is not moved to the new conflicting point $P$ (Figure 2).

The circles $O_{1}$ and $O_{S}$ determine the characteristic points of the trajectory marked in Figure 2 by 1, 2, and 3 . The way of determining these points is as follows:

- $\quad$ Point 1: the point where the trajectory $\boldsymbol{T}_{A}$ is tangent to the circle $O_{1}$;

- $\quad$ Point 2: the point where circle $O_{1}$ is tangent to the circle $O_{S}$;

- $\quad$ Point 3: the point where a straight line passing through point $A_{2}$ is tangent to the circle $O_{S}$.

Thus, the $T_{A}$ trajectory consists of four parts:

1. Segment $\overline{A_{1}, 1}=\boldsymbol{R}_{1}-\boldsymbol{R}_{A_{1}}$, where $\boldsymbol{R}_{1}$ is the vector representing point 1;

2. Arc 1,2, connecting points 1 and 2;

3. Arc 2,3, connecting points 2 and 3;

4. Segment $\overline{3, A_{2}}=\boldsymbol{R}_{A_{2}}-\boldsymbol{R}_{3}$, where $\boldsymbol{R}_{3}$ is the vector representing point 3 .

Tjectory $\boldsymbol{T}_{B}$. consists of one segment $\overline{B_{1}, B_{2}}=\boldsymbol{R}_{B_{2}}-\boldsymbol{R}_{B_{1}}$. We assume that both aircraft move at the same speed.

\subsubsection{Coordinates of the Characteristic Point 1}

The determination of characteristic point 1 is important for both the Dubins and the $3 \mathrm{HC}$ methods. At this characteristic point 1 , the conflict resolution maneuvers begin. The 
choice of this point is important both for traffic safety and for extending the flight path The later aircraft A begins its maneuvers, the smaller the safety margin is as the aircraft approach each other throughout the duration of the conflict; additionally, the sharper the maneuvers will be. On the other hand, the earlier the aircraft starts maneuvers, the greater the increase in route length and the smoother the maneuver. In any case, it must be ensured that the minimum separation is not violated before aircraft A reaches point 1.

We will determine the coordinates of point 1 as follows:

$$
\boldsymbol{R}_{1}=\boldsymbol{R}_{A_{1}}+\boldsymbol{R}_{A_{1}, 1}
$$

We denote the length of the segment $\overline{A_{1}, 1}$ by $L_{A_{1}, 1}$. Then the vector describing the segment $\overline{A_{1}, 1}$ can be represented as follows:

$$
\boldsymbol{R}_{A_{1}, 1}=L_{A_{1}, 1} \cdot \boldsymbol{e}_{1, O_{S}}
$$

The unit vector $\boldsymbol{e}_{1, O_{S}}$ is calculated in the following way:

$$
\boldsymbol{e}_{1, O_{S}}=\frac{\boldsymbol{R}_{A_{1}, O_{S}}}{L_{A_{1}, O_{S}}}
$$

The denominator of dependence (7) includes the length of the segment $\overline{A_{1}, O_{S}}$, which we will calculate as follows:

$$
L_{A_{1}, O_{S}}=\sqrt{\boldsymbol{R}_{A_{1}, O_{S}}^{\mathrm{T}} \cdot \boldsymbol{R}_{A_{1}, O_{S}}}
$$

The length $L_{A_{1}, 1}$ in Formula (6) can be determined as follows:

$$
L_{A_{1}, 1}=L_{A_{1}, O_{S}}-L_{1, O_{S}}
$$

where, according to Pythagoras' theorem:

$$
L_{1, O_{S}}=\sqrt{\left(r_{O_{1}}+r_{O_{S}}\right)^{2}-r_{O_{1}}^{2}}
$$

After characteristic point 1 , the aircraft proceeds via the designated path towards characteristic point 2 .

\subsubsection{Coordinates of the Characteristic Point 2}

In characteristic point 2, the aircraft starts moving along the perimeter of the circle $O_{S}$. We calculate the vector of coordinates of point 2 in the following way:

$$
\boldsymbol{R}_{2}=\boldsymbol{R}_{O_{1}}+\boldsymbol{R}_{O_{1}, 2}=\boldsymbol{R}_{O_{1}}+r_{O_{1}} \cdot \boldsymbol{e}_{O_{1}, O_{S}}
$$

We determine vector $\boldsymbol{R}_{O_{1}}$ of the center of the circle $O_{1}$ as follows:

$$
\boldsymbol{R}_{O_{1}}=\boldsymbol{R}_{1}+\boldsymbol{R}_{1, O_{1}}=\boldsymbol{R}_{1}+r_{O_{1}} \cdot \boldsymbol{e}_{1, O_{1}}
$$

The unit vector $\boldsymbol{e}_{1, O_{1}}$, perpendicular to the segment $\overline{A_{1}, O_{S}}$ can be determined in the following way:

$$
\boldsymbol{e}_{1, \mathrm{O}_{1}}=\boldsymbol{e}_{n} \times \boldsymbol{e}_{1, \mathrm{O}_{s}}
$$

where the normal vector $\boldsymbol{e}_{n}$ is equal:

$$
\boldsymbol{e}_{n}^{T}=[0,0,1]
$$


We may determine the unit vector $\boldsymbol{e}_{O_{1}, O_{S}}$ as follows:

$$
\boldsymbol{e}_{O_{1}, O_{S}}=\frac{\boldsymbol{R}_{O_{1}, O_{S}}}{L_{O_{1}, O_{S}}}=\frac{\boldsymbol{R}_{O_{1}, O_{S}}}{\boldsymbol{R}_{O_{1}}+r_{O_{S}}}
$$

After characteristic point 2, the aircraft proceeds via a designated path towards characteristic point 3 .

\subsubsection{Coordinates of the Characteristic Point 3}

At characteristic point 3, aircraft A terminates the circular motion and begins to move straight down to the $T_{A}$ trajectory endpoint. We may identify characteristic point 3 as the point where a straight line passing through the point $A_{2}$ is tangent to the circle $O_{S}$. Two cases should be considered.

1. when $y_{A_{1}} \geq y_{A_{2}}$

$$
\begin{gathered}
x_{3}=x_{O_{S}}+\frac{r_{O_{S}}}{L_{O_{S}, A_{2}}^{2}}\left[r_{O_{S}}\left(x_{\mathrm{A}_{2}}-x_{O_{S}}\right)-\left(y_{\mathrm{A}_{2}}-y_{O_{S}}\right) \sqrt{L_{O_{S}, A_{2}}^{2}-r_{O_{S}}{ }^{2}}\right] \\
y_{3}=y_{O_{S}}-\sqrt{r_{O_{S}}{ }^{2}-\left(x_{3}-x_{O_{S}}\right)^{2}}
\end{gathered}
$$

2. when $y_{A_{1}}<y_{A_{2}}$

$$
\begin{gathered}
x_{3}=x_{O_{S}}+\frac{r_{O_{S}}}{L_{O_{S}, \mathrm{~A}_{2}}^{2}}\left[r_{O_{S}}\left(x_{A_{2}}-x_{O_{S}}\right)+\left(y_{\mathrm{A}_{2}}-y_{O_{S}}\right) \sqrt{L_{O_{S}, \mathrm{~A}_{2}}^{2}-r_{O_{S}}^{2}}\right] \\
y_{3}=y_{O_{S}}+\sqrt{r_{O_{S}}^{2}-\left(x_{3}-x_{O_{S}}\right)^{2}}
\end{gathered}
$$

After characteristic point 3 , the aircraft proceeds via a designated path so as to resume the endpoint of trajectory $\boldsymbol{T}_{A}$.

\subsubsection{Trajectory Length and Flight Duration}

After determining all trajectory characteristic points' coordinates, we determine each segment length and flight duration between characteristic points (Figure 2).

The trajectory is determined by the sequence of characteristic points $\boldsymbol{R}_{A_{1}}, \boldsymbol{R}_{1}, \boldsymbol{R}_{2}, \boldsymbol{R}_{3}, \boldsymbol{R}_{A_{2}}$ and its length:

$$
L_{A_{1}, A_{2}}^{n e w}=L_{A_{1}, 1}+L_{1,2}+L_{2,3}+L_{3, A_{2}}
$$

$L_{A_{1}, 1}$ is given by Formula (9)

$$
L_{1,2}=\alpha_{1,2} \cdot r_{O_{1}}
$$

where

$$
\begin{gathered}
\alpha_{1,2}=\arccos \frac{\boldsymbol{R}_{1} \cdot \boldsymbol{R}_{2}}{r_{O_{1}}{ }^{2}} \\
L_{2,3}=\alpha_{2,3} \cdot r_{O_{S}}
\end{gathered}
$$

where

$$
\begin{gathered}
\alpha_{2,3}=\arccos \frac{\boldsymbol{R}_{2} \cdot \boldsymbol{R}_{3}}{r_{O_{S}}{ }^{2}} \\
L_{3, A_{2}}=\sqrt{\left(\boldsymbol{R}_{A_{2}}-\boldsymbol{R}_{3}\right)^{\mathrm{T}} \cdot\left(\boldsymbol{R}_{A_{2}}-\boldsymbol{R}_{3}\right)}
\end{gathered}
$$

Assuming that during conflict resolution the aircraft speed is constant, flight time is given by the relationship:

$$
t_{A_{1}, A_{2}}^{n e w}=\frac{L_{A_{1, A_{2}}}^{n e w w}}{V_{A}}
$$


In the absence of a conflict, the flight time would be equal:

$$
t_{A_{1}, A_{2}}=\frac{L_{A_{1}, A_{2}}}{V_{A}}
$$

where

$$
L_{A_{1}, A_{2}}=\sqrt{\left(\boldsymbol{R}_{A_{2}}-\boldsymbol{R}_{A_{1}}\right)^{\mathrm{T}} \cdot\left(\boldsymbol{R}_{A_{2}}-\boldsymbol{R}_{A_{1}}\right)}
$$

The additional flight time necessary for aircraft $\mathrm{A}$ to solve the conflict situation is:

$$
\Delta t=t_{A_{1}, A_{2}}^{n e w}-t_{A_{1}, A_{2}}
$$

In this case, then one aircraft flew via the Dubins method for the purpose to resolve a conflict with another one flying via the flight planned route (via unmodified trajectory), the comparison of flight distance and time can be evaluated.

\subsection{Triple Heading Change (3HC) Method}

The $3 \mathrm{HC}$ method to resolve conflicts within the airborne collision avoidance system was previously described in [25]. It involves three heading changes of aircraft A to bypass the collision point (Figure 3). The general algorithm of the $3 \mathrm{HC}$ conflict resolution method in a version adapted to the concept presented in this paper is as follows:

1. At point 1, aircraft A makes a turn in the horizontal plane and starts a flight towards point $\mathrm{E}, \boldsymbol{R}_{E}^{\mathrm{T}}=\left[x_{\mathrm{E}}, y_{\mathrm{E}}\right]$ located on a line perpendicular to the initial flight path of aircraft $\mathrm{A}$ at a distance $D$ from the collision point $O_{s}$. This distance is dependent on the position of point 1 , the headings, and the flight parameters of both aircraft. We must select it in such a way as to ensure the minimum separation $d_{s}$ required by international regulations [49].

2. After reaching point $E$, aircraft $\mathrm{A}$ makes a second change of heading, starting the flight towards point $A_{2}$, i.e., the endpoint of the trajectory $\boldsymbol{T}_{A}$.

3. After reaching point $A_{2}$, aircraft $\mathrm{A}$ returns to its original heading.

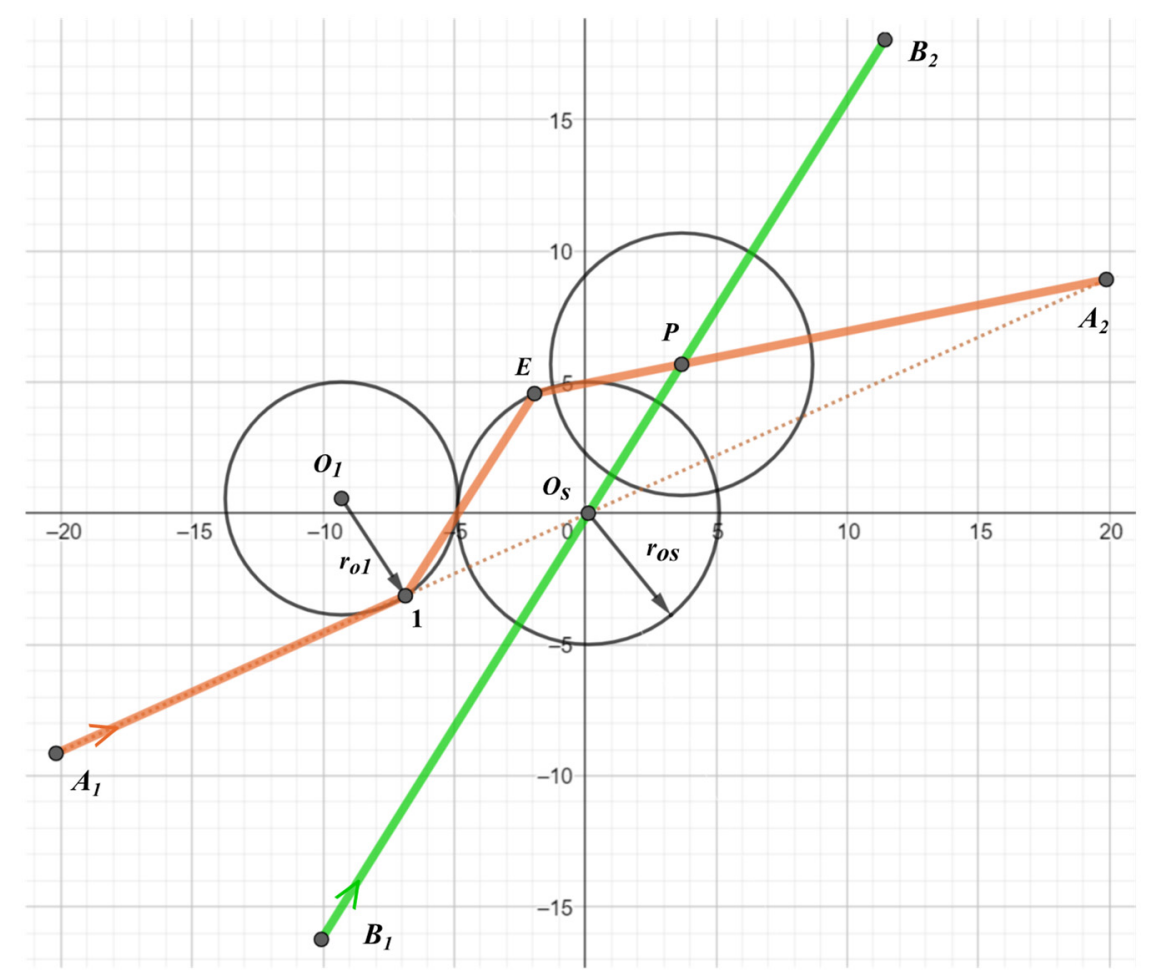

Figure 3. Graphic illustration of the 3HC method. 
The main problem in the $3 \mathrm{HC}$ method is the selection of its parameters, especially the coordinates of point 1 and the radius of the circle $O_{s}$ (location of point E). In the paper [25] we proposed their determination by simulation using a model built on the basis of colored Petri nets.

The aircraft trajectories $T_{A}$ and $T_{B}$ determined according to the $3 \mathrm{HC}$ method are presented in Figure 3. They can be schematically described as follows:

$$
\begin{gathered}
\boldsymbol{T}_{A}: \boldsymbol{R}_{A_{1}} \rightarrow \boldsymbol{R}_{1} \rightarrow \boldsymbol{R}_{\mathrm{E}} \rightarrow \boldsymbol{R}_{A_{2}} \\
\boldsymbol{T}_{B}: \boldsymbol{R}_{B_{1}} \rightarrow \boldsymbol{R}_{B_{2}}
\end{gathered}
$$

The coordinates of the vector $\boldsymbol{R}_{E}$ we determine as follows:

$$
\boldsymbol{R}_{E}=\boldsymbol{R}_{O_{\mathrm{s}}}+\boldsymbol{R}_{O_{\mathrm{s}}, E}=\boldsymbol{R}_{O_{\mathrm{s}}}+r_{O_{s}} \cdot \boldsymbol{e}_{O_{\mathrm{s}}, E}
$$

The unit vector $\boldsymbol{e}_{\mathrm{O}_{\mathrm{s}}, E}$, perpendicular to the segment $\overline{A_{1}, O_{S}}$ can be determined in the following way:

$$
\boldsymbol{e}_{\mathrm{O}_{\mathrm{s}}, E}=\boldsymbol{e}_{n} \times \boldsymbol{e}_{1, \mathrm{O}_{s}}
$$

where the normal vector $e_{n}$ is equal:

$$
\boldsymbol{e}_{n}^{T}=[0,0,1]
$$

The flight distance in accordance with the concept of the $3 \mathrm{HC}$ method is:

$$
L_{A_{1}, A_{2}}^{3 \mathrm{HC}}=L_{A_{1}, 1}+L_{1, E}+L_{E, A_{2}}
$$

where

$L_{A_{1}, 1}$ we determine with the use of Formulas (8)-(10),

$$
\begin{gathered}
L_{1, E}=\sqrt{\left(\boldsymbol{R}_{E}-\boldsymbol{R}_{1}\right)^{\mathrm{T}} \cdot\left(\boldsymbol{R}_{E}-\boldsymbol{R}_{1}\right)} \\
L_{E, A_{2}}=\sqrt{\left(\boldsymbol{R}_{A_{2}}-\boldsymbol{R}_{E}\right)^{\mathrm{T}} \cdot\left(\boldsymbol{R}_{A_{2}}-\boldsymbol{R}_{E}\right)}
\end{gathered}
$$

The flight time according to the route consistent with the $3 \mathrm{HC}$ method concept is:

$$
t_{A_{1}, A_{2}}^{3 \mathrm{HC}}=\frac{L_{A_{1}, A_{2}}^{3 \mathrm{HC}}}{v_{A}}
$$

In the absence of a conflict, the straight-line flight time between points $A_{1}$ and $A_{2}$ is:

$$
t_{A_{1}, A_{2}}=\frac{L_{A_{1}, A_{2}}}{v_{A}}
$$

Therefore, the additional flight time resulting from the need to resolve the conflict, in the case of the $3 \mathrm{HC}$ method is:

$$
\Delta t^{3 \mathrm{HC}}=t_{A_{1}, A_{2}}^{3 \mathrm{HC}}-t_{A_{1}, A_{2}}
$$

In this case, then one aircraft flew via the $3 \mathrm{HC}$ method for the purpose to resolve a conflict with another one flying via flight planned route (via unmodified trajectory), the comparison of aircraft flight distance and time can be evaluated.

\subsection{Optimization Scheme}

As has already been mentioned, it is important to select the parameters of the model in such a way that the separation between the aircraft is maintained at any time during the conflict resolution. At the same time, we strive to make as little detour as possible, which 
takes place when the radius $r_{O_{S}}$ is as small as possible. For both methods, we selected these parameters by simulation. Its general scheme is shown in Figure 4.

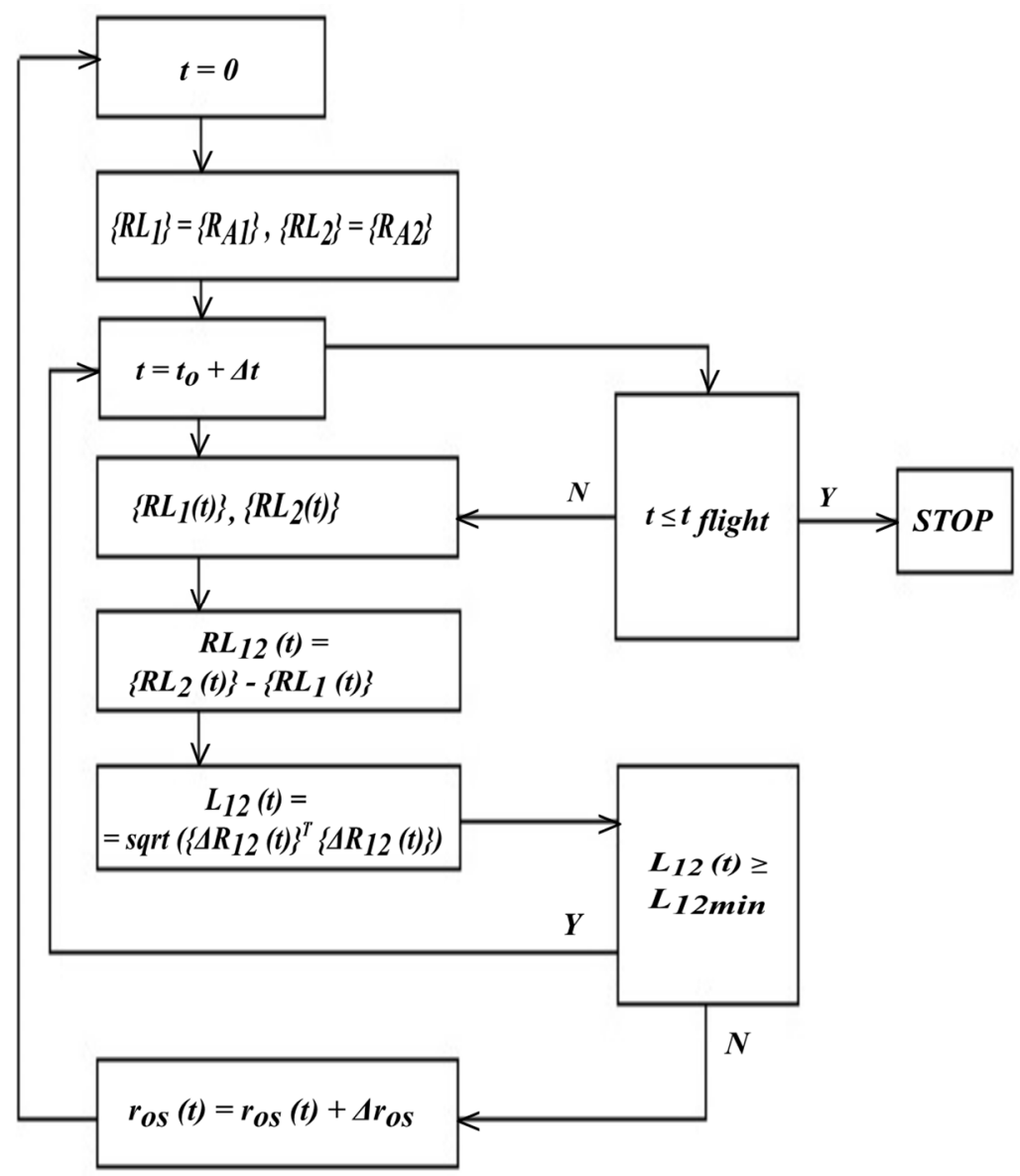

Figure 4. Optimization scheme.

As the endpoint of the simulation, we choose time $t_{\text {flight }}$, after which both aircraft have passed the destination points $A_{2}$ and $B_{2}$. Throughout the simulation, we monitor the positions $\boldsymbol{R}_{A}(t)$ and $\boldsymbol{R}_{B}(t)$ of aircraft $\mathrm{A}$ and $\mathrm{B}$, respectively, checking that the minimum separation $L_{\text {min }}=5 \mathrm{~nm}$ has not been violated. If at any moment the separation is violated, then we increase the radius $r_{O_{S}}(0.1 \mathrm{~nm})$ and repeat the simulation.

\subsection{Dubins-like Trajectory Using Non-Circle Curves}

In our method using the Dubins trajectory, the aircraft moves along a circular arc. However, in some cases, it may be beneficial that the aircraft follows a different curve, for example, an ellipse. Wanting to include the possibility of determining trajectories not only along the arc, but also along other curves we will determine the coordinates of characteristic points using the parametric approach. In this approach, the $C(\xi)$ curve, along which the aircraft moves, is a set of points $\boldsymbol{R}_{j}(\xi)$, approximated using the function $N(\xi)$ based on five characteristic points $P_{1}, \ldots, P_{5}$, shown in Figure 5 . The values of function $N(\xi)$ for those characteristic points are presented in Appendix A (Table A1).

$$
\boldsymbol{R}_{j}(\xi)=\sum_{i=1}^{5} N_{i}(\xi) \boldsymbol{R}_{P_{i}}, 0 \leq \xi \leq 1
$$

where

$$
\boldsymbol{R}_{P_{1}}=\boldsymbol{R}_{O_{S}}-r_{O_{S}} \boldsymbol{e}_{1, O_{S}}
$$




$$
\begin{gathered}
\boldsymbol{R}_{P_{2}}=\boldsymbol{R}_{O_{S}}-\frac{1}{2} r_{O_{S}} \boldsymbol{e}_{1, O_{s}}+\frac{\sqrt{3}}{2} r_{O_{S}} \boldsymbol{e}_{1, O_{1}} \\
\boldsymbol{R}_{P_{3}}=\boldsymbol{R}_{O_{S}}+r_{O_{S}} \boldsymbol{e}_{1, O_{1}} \\
\boldsymbol{R}_{P_{4}}=\boldsymbol{R}_{O_{S}}+\frac{1}{2} r_{O_{S}} \boldsymbol{e}_{1, O_{s}}+\frac{\sqrt{3}}{2} r_{O_{S}} \boldsymbol{e}_{1, O_{1}} \\
\boldsymbol{R}_{P_{5}}=\boldsymbol{R}_{O_{S}}+r_{O_{S}} \boldsymbol{e}_{1, O_{s}}
\end{gathered}
$$

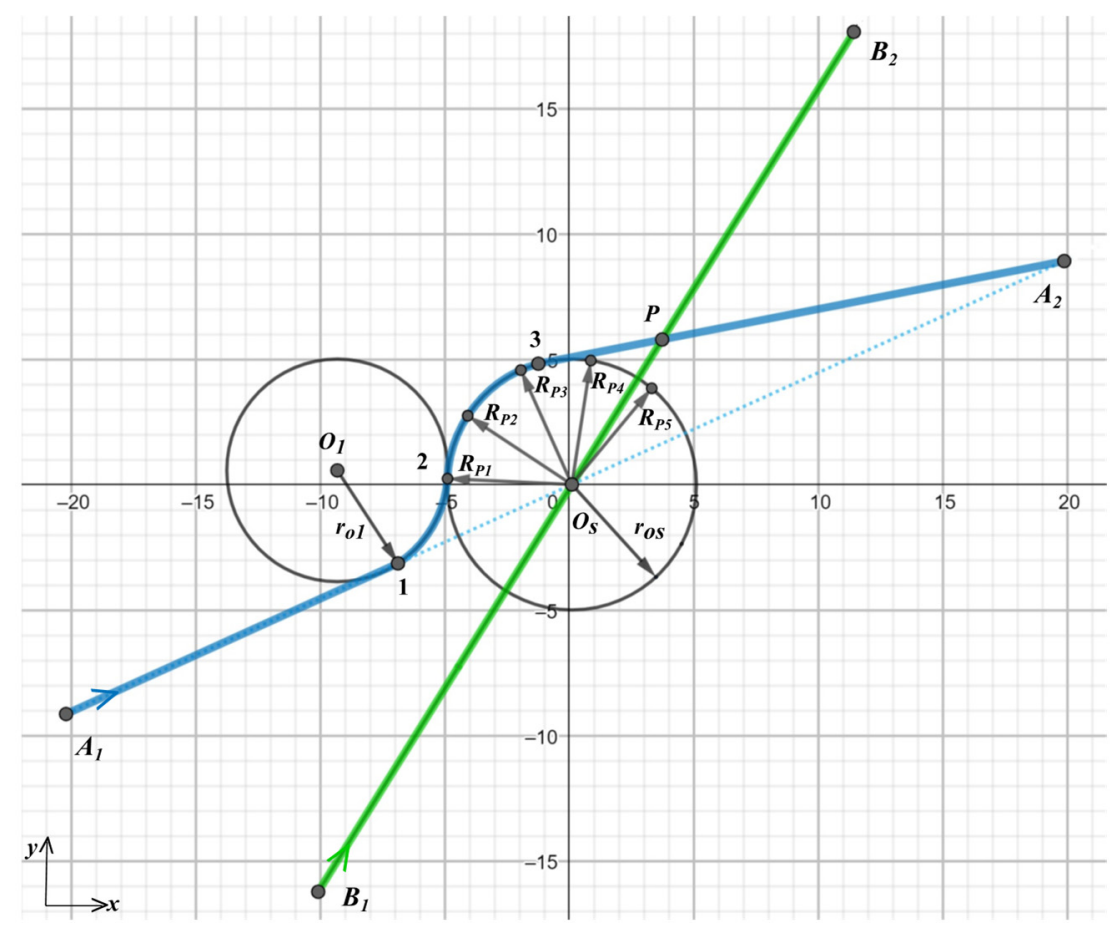

Figure 5. Characteristic points $\boldsymbol{R}_{P_{1}}, \ldots, \boldsymbol{R}_{P_{5}}$ used to approximate curve $C(\xi)$ points (see Table A1).

As in other methods, the most important thing is to determine the characteristic points.

We may determine the $R_{3}(\xi)$ point coordinates' vector by solving the adequate nonlinear equation upon parameter $\xi$. For this purpose, we will use the fact that the $\boldsymbol{R}_{3, A_{2}}$ vector is tangent to the $O_{S}$ circle, so the tangential vector $\boldsymbol{\tau}$ (Figure 2) and $\boldsymbol{R}_{3, A_{2}}$ are parallel. Thus:

$$
\frac{\boldsymbol{\tau}^{\mathrm{T}} \cdot \boldsymbol{R}_{3, A_{2}}}{|\boldsymbol{\tau}| \cdot\left|\boldsymbol{R}_{3, A_{2}}\right|}=1
$$

where:

$$
\boldsymbol{\tau}=\frac{\frac{d \boldsymbol{R}_{j}(\xi)}{d \xi}}{\left|\frac{d \boldsymbol{R}_{j}(\xi)}{d \xi}\right|}=\frac{\sum_{i=1}^{5} \frac{d N_{i}(\xi) \boldsymbol{R}_{P_{i}}}{d \xi}}{\left|\frac{d \boldsymbol{R}_{j}(\xi)}{d \xi}\right|}
$$

We define function $\Phi(\xi)$ :

$$
\Phi(\xi)=\boldsymbol{\tau}^{\mathrm{T}} \cdot \boldsymbol{R}_{3, A_{2}}-\left|\boldsymbol{\tau}^{\mathrm{T}}\right| \cdot\left|\boldsymbol{R}_{3, A_{2}}\right|=\boldsymbol{\tau}^{\mathrm{T}} \cdot\left(\boldsymbol{R}_{A_{2}}-\boldsymbol{R}_{3}(\xi)\right)-\left|\boldsymbol{\tau}^{\mathrm{T}}\right| \cdot\left|\boldsymbol{R}_{A_{2}}-\boldsymbol{R}_{3}(\xi)\right|
$$

Given the Formula (49) and the fact that $\left|\tau^{\mathrm{T}}\right|=1$ we obtain the equation:

$$
\Phi(\xi)=\boldsymbol{\tau}^{\mathrm{T}} \cdot\left(\boldsymbol{R}_{A_{2}}-\boldsymbol{R}_{3}(\xi)\right)-\left|\boldsymbol{R}_{A_{2}}-\boldsymbol{R}_{3}(\xi)\right|=0
$$

We may solve non-linear Equation (40) upon parameter $\xi$ numerically using the Newton-Rapson method. In our case, we used the Non-Linear Programming (NLP) solver 
available in the Maple package. This way we determine the $\xi_{3}$ parameter and thus the $\boldsymbol{R}_{3}\left(\xi_{3}\right)$ vector:

$$
\boldsymbol{R}_{3}\left(\xi_{3}\right)=\sum_{i=1}^{5} N_{i}\left(\xi_{3}\right) \boldsymbol{R}_{P_{i}}, 0 \leq \xi \leq 1
$$

The $\boldsymbol{R}_{2}$ point is located between semicircle points $P_{1}, \ldots, P_{5}$, determined by vectors $\boldsymbol{R}_{P_{i}}$, where $i=1, \ldots, 5$. To determine the $\boldsymbol{R}_{2}$ point corresponding to $\xi_{3}$ parameter, we must minimize the non-linear algebraic function:

$$
\Phi(\xi)=\left(\boldsymbol{R}_{2}(\xi)-\boldsymbol{R}_{2}\right)^{\mathrm{T}} \cdot\left(\boldsymbol{R}_{2}(\xi)-\boldsymbol{R}_{2}\right)
$$

The $\boldsymbol{R}_{1}$ is determined in the same way as in the Dubins trajectory.

\section{Analysis of the Effectiveness of Two Methods}

Using the presented methodology, we compared the proposed methods in terms of their effectiveness in resolving a conflict situation, i.e., when the angles of both trajectories at the starting point of the simulation are 35 and 90 degrees, respectively. We will present this comparison using an example. The coordinates of the starting and ending points (expressed in nautical miles) were adopted as follows:

$$
\begin{aligned}
& \boldsymbol{R}_{A_{1}}^{T}=[30,41, z] \\
& \boldsymbol{R}_{A_{2}}^{T}=[70,59, z] \\
& \boldsymbol{R}_{B_{1}}^{T}=[40,34, z] \\
& \boldsymbol{R}_{B_{2}}^{T}=[61,68, z]
\end{aligned}
$$

The speed of the aircraft is $v_{1}=v_{2}=500 \mathrm{kt}$. The coordinates of the conflict point calculated from (53) are as follows:

$$
\boldsymbol{R}_{\mathrm{Os}}^{T}=[49.84,49.92, z]
$$

\subsection{Conflict Resolution by the Dubins and $3 \mathrm{HC}$ Methods ( $35^{\circ}$ Case)}

Numerical investigation of the conflict resolution while using the Dubins and the $3 \mathrm{HC}$ methods when the angle (for both trajectories) at the starting point of the simulation is $35^{\circ}$, is presented in Figure 6a (Dubins) and Figure $6 \mathrm{~b}(3 \mathrm{HC})$.

Both aircraft, as for the Dubins and as for the $3 \mathrm{HC}$ variant, fly via upper/left part of the circle with radius $r_{O_{S}}$.

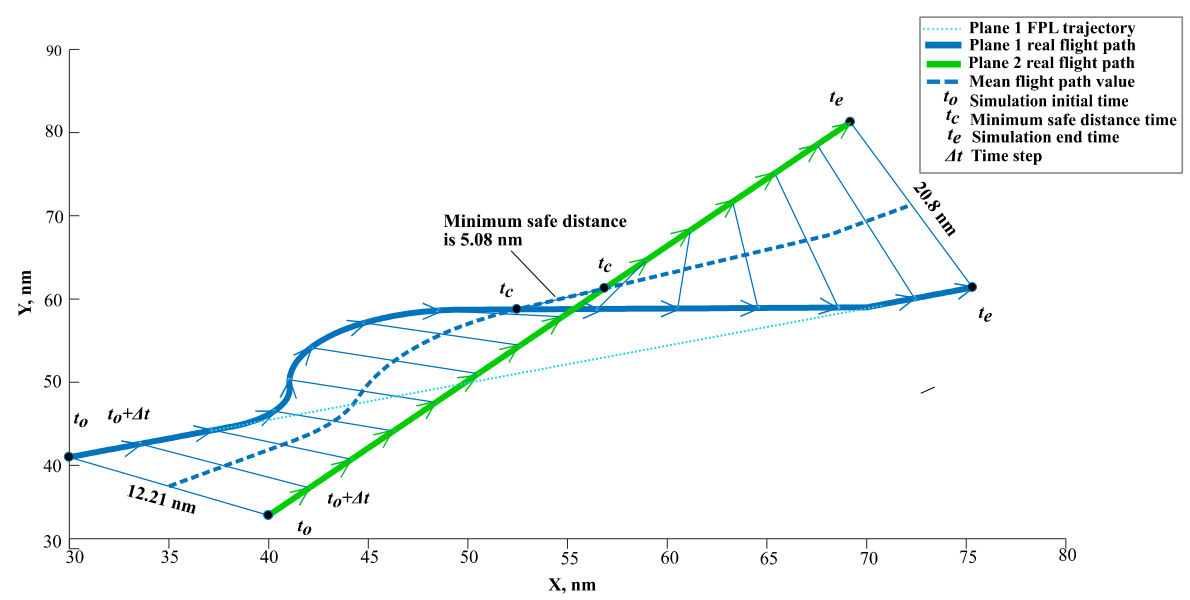

(a)

Figure 6. Cont. 


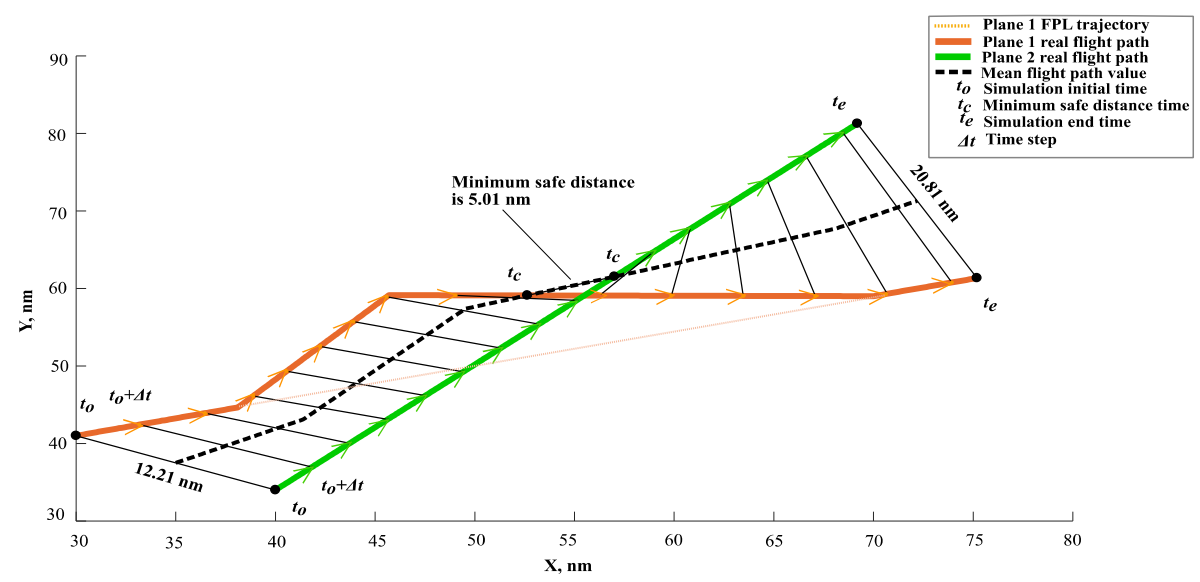

(b)

Figure 6. Aircraft A and B trajectories with an initial angle of $35^{\circ}$ for the Dubins (a) and the $3 \mathrm{HC}$ (b) methods.

Using the optimization procedure as discussed in Section 2.3, numerical investigation results when the angle of both trajectories at the starting point of the simulation is $35^{\circ}$ using the Dubins method, show that for such angle between flight trajectories, i.e., $35^{\circ}$, the minimum radius $r_{O_{S}}$ for which the separation is assured at any moment of the simulation is $8.8 \mathrm{~nm}$. In such a case, the minimum safe distance $L_{A, B}(t)$ between the aircraft is $5.08 \mathrm{~nm}$ (detected at $232 \mathrm{~s}$ from the beginning of the simulation). Meanwhile, for the $3 \mathrm{HC}$ method, it was established that while the angle of both trajectories at the starting point of the simulation is $35^{\circ}$, the minimum radius $r_{O_{S}}$ for which the separation is assured at any moment of the simulation is $10.10 \mathrm{~nm}$. In this case, the minimum safe distance $L_{A, B}(t)$ between the aircraft is $5.01 \mathrm{~nm}$ (detected at $232 \mathrm{~s}$ from the beginning of the simulation).

The Dubins and 3HC mean flight path distance values, taking both minimum and maximum values while the angle (for both trajectories) at the starting point of the simulation is $35^{\circ}$, are shown in Figure 7.

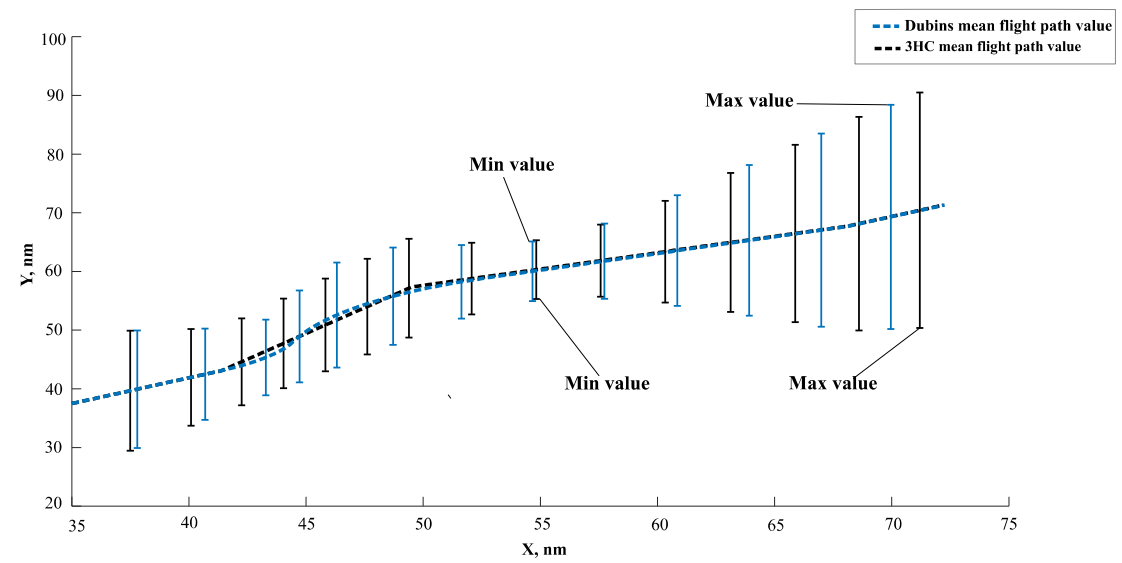

Figure 7. The Dubins and the $3 \mathrm{HC}$ mean flight path distance values $\left(35^{\circ}\right.$ case $)$.

Numerical results for the conflict resolution using the Dubins method when the angle (of both trajectories) at the starting point of the simulation is $35^{\circ}$ is slightly more effective than for the $3 \mathrm{HC}$ method because the resolution via the Dubins method allows to maintain a minimum safe distance between aircraft at any moment of the flight and to operate via the circle with a smaller radius $r_{O_{S}}$ when resolving the conflict. 


\subsection{Conflict Resolution by the Dubins and the $3 \mathrm{HC}$ Methods $\left(90^{\circ}\right.$ Case)}

Numerical investigation of conflict resolution using the Dubins and the $3 \mathrm{HC}$ methods of both aircraft (in two dimensions) when the angle (for both trajectories) at the starting point of the simulation is $90^{\circ}$, is presented in Figure 8 a (Dubins) and Figure $8 \mathrm{~b}(3 \mathrm{HC})$. Moreover, in the Dubins variant, the aircraft flies via the upper part of the circle with a radius $r_{O_{S}}$, meanwhile, in the $3 \mathrm{HC}$ variant, the aircraft flies via the bottom/right part of the same circle (this was impacted by an initial angle of $90^{\circ}$ between the aircraft flight trajectories while the safe and rational solution cannot be found, and due to the constraint that if the radius $r_{O_{S}}$ value reaches $15 \mathrm{~nm}$, as a logical solution, the aircraft should decide to fly via the bottom part of the circle with a radius $r_{O_{S}}$ ) so as to assure a safe and rational solution.

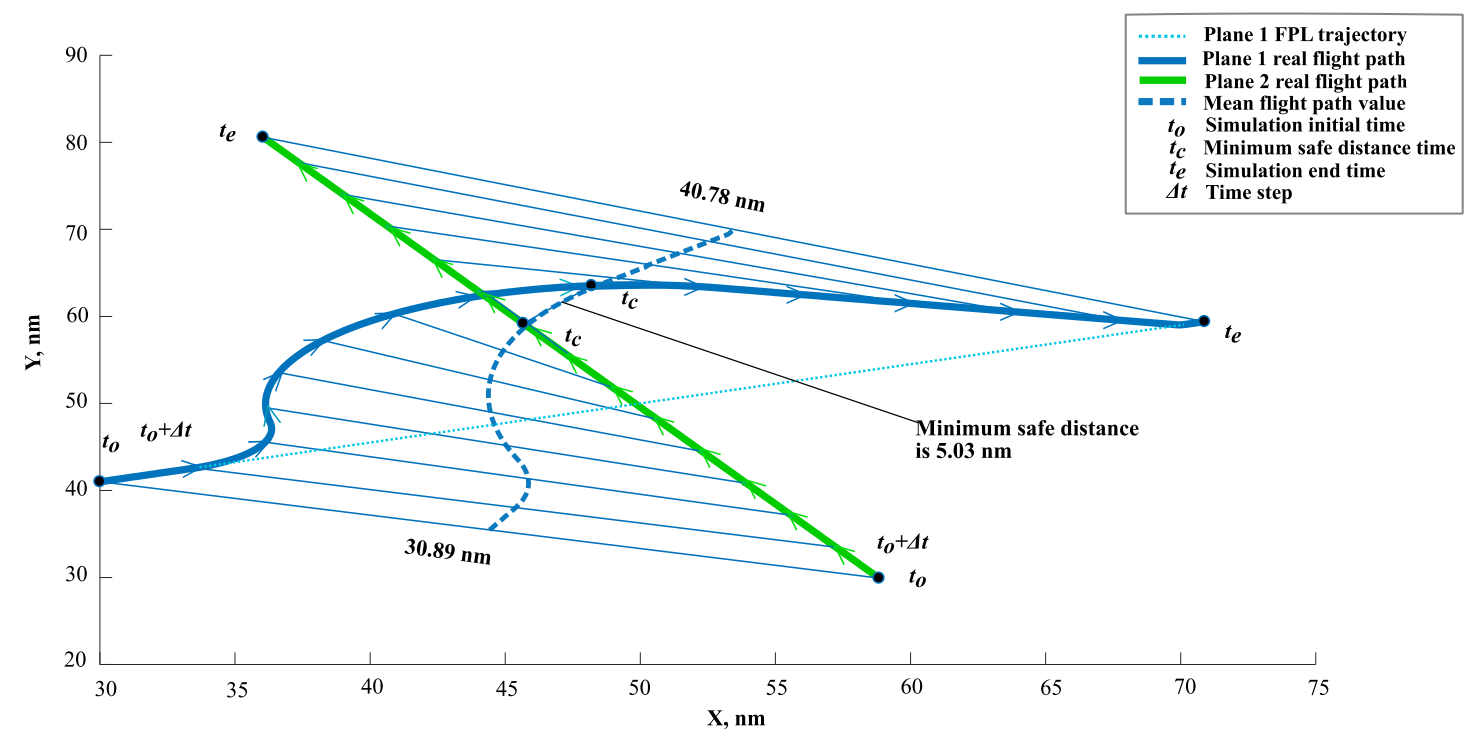

(a)

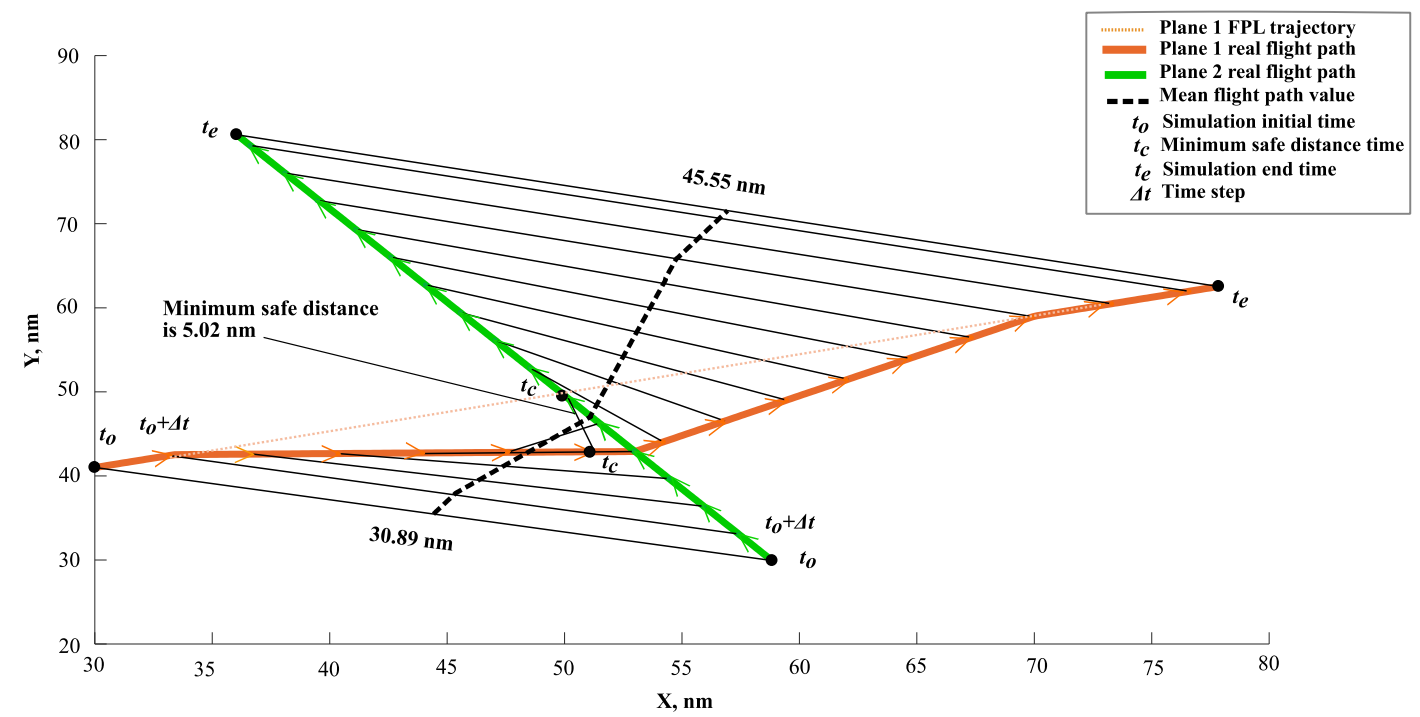

(b)

Figure 8. Aircraft A and B trajectories with an initial angle of $90^{\circ}$ for the Dubins (a) and the $3 \mathrm{HC}$ (b) methods. 
Using the optimization procedure as discussed in Section 2.3, numerical investigation results when the angle (for both trajectories) at the starting point of the simulation is $90^{\circ}$ using the Dubins method, show that the minimum circle radius $r_{O_{S}}$ for which the separation is assured at any moment of the simulation is $13.7 \mathrm{~nm}$. In such a case, the minimum safe distance $L_{A, B}(t)$ between the aircraft is $5.03 \mathrm{~nm}$ (as detected at $234 \mathrm{~s}$ from the beginning of the simulation). Meanwhile, the $3 \mathrm{HC}$ method results show that when the angle (for both trajectories) at the starting point of the simulation is $90^{\circ}$, the minimum radius $r_{O_{S}}$ for which the separation is assured at any moment of the simulation is $7.7 \mathrm{~nm}$. In this case, the minimum safe distance $L_{A, B}(t)$ between the aircraft is $5.02 \mathrm{~nm}$ (detected at $136 \mathrm{~s}$ from the beginning of the simulation).

The Dubins and 3HC mean flight path distance values, taking both minimum and maximum values when the angle (for both trajectories) at the starting point of the simulation is $90^{\circ}$, are shown in Figure 9.

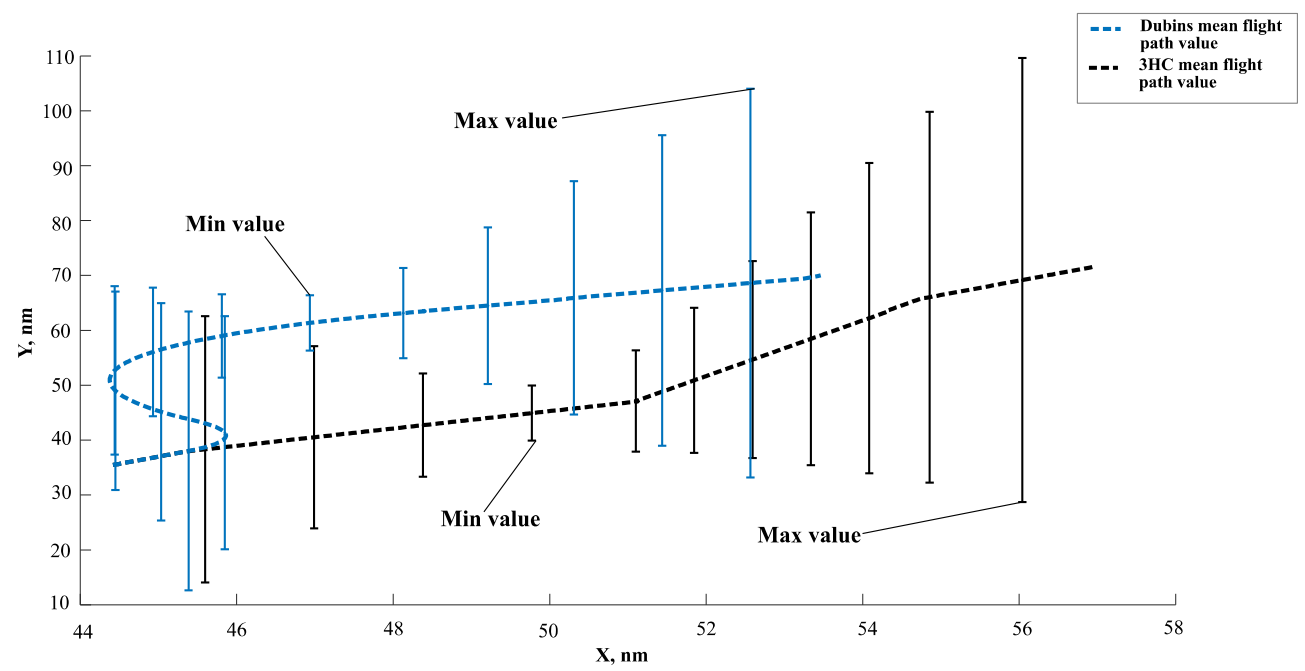

Figure 9. The Dubins and the $3 \mathrm{HC}$ mean flight path distance values $\left(90^{\circ}\right.$ case).

Numerical results for conflict resolution using the $3 \mathrm{HC}$ method when the angle (for both trajectories) at the starting point of the simulation is $90^{\circ}$ are slightly more effective than the Dubins method. The conflict resolution via the $3 \mathrm{HC}$ method allows to maintain a minimum safe distance between aircraft at any moment of flight and operate via the circle with a smaller radius $r_{O_{S}}$ while resolving the conflict, i.e., to assure a safe and rational solution.

\subsection{The Comparison of the Dubins and the 3HC Methods}

The basic criteria for comparing the effectiveness of both methods when the angles (for both trajectories) at the starting point of the simulation are $35^{\circ}$ and $90^{\circ}$, respectively, are the time and length of the route traveled by aircraft $\mathrm{A}$ in accordance with the adopted trajectory. The results of the comparison are presented in Tables 1 and 2.

Table 1. Route length and time traveled by aircraft $\left(35^{\circ}\right.$ case).

\begin{tabular}{ccccc}
\hline & \multicolumn{2}{c}{ Dubins } & \multicolumn{2}{c}{ 3HC } \\
& Length [nm] & Time [s] & Length [nm] & Time [s] \\
\hline Segment 1 & 8.89 & 64.01 & 8.89 & 64.01 \\
Segment 2 & 6 & 43.20 & 16.35 & 117.75 \\
Segment 3 & 14.13 & 101.76 & 24.31 & 175.02 \\
Segment 4 & 20.31 & 146.25 & - & - \\
Total: & 49.33 & 355.22 & 49.55 & 356.78 \\
\hline
\end{tabular}


It is evident from the results presented for both methods (when the angle (of both trajectories) at the starting point of the simulation is $35^{\circ}$ ) that they are very similar, but a slightly smaller additional distance has to be covered while using the method of conflict resolution based on the Dubins trajectories.

It is evident that the results of both methods (when the angle (of both trajectories) at the starting point of the simulation is $90^{\circ}$ ) show that a slightly smaller additional distance is covered while using the method of conflict resolution based on the $3 \mathrm{HC}$ method than the Dubins method. It can be explained by the fact that in the case of the $3 \mathrm{HC}$ method, optimal $r_{O_{S}}$ is smaller, i.e., $7.7 \mathrm{~nm}$ than in the Dubins case, i.e., $13.7 \mathrm{~nm}$. The reason is the angle of $90^{\circ}$ between trajectories at the starting point of the simulation where the constraint is set such so that if the radius $r_{O_{S}}$ value reaches $15 \mathrm{~nm}$, as a logical solution, the aircraft should decide to fly via the bottom part of a circle with a radius $r_{O_{S}}$. Thus, such an interactive optimization allows to reach the solution and assure safe separation between aircraft and produces a shorter route length and time traveled by aircraft.

Table 2. Route length and time traveled by aircraft $\left(90^{\circ}\right.$ case).

\begin{tabular}{ccccc}
\hline & \multicolumn{2}{c}{ Dubins } & \multicolumn{2}{c}{ 3HC } \\
& Length [nm] & Time [s] & Length [nm] & Time [s] \\
\hline Segment 1 & 3.04 & 21.88 & 3.04 & 21.88 \\
Segment 2 & 6.5 & 46.81 & 19.6 & 141.09 \\
Segment 3 & 27.03 & 194.65 & 23.41 & 168.57 \\
Segment 4 & 17.29 & 124.48 & - & - \\
Total: & 53.86 & 387.82 & 46.05 & 331.54 \\
\hline
\end{tabular}

Another important criterion for evaluating the performance of a conflict resolution method is fuel consumption [50,51]. It is usually referred to in relation to a service provided (the number of passengers or ton of freight) and the distance flown. It can be expressed in different ways, for example, by liters of fuel consumed per passenger per kilometer [52].

As an exemplary aircraft, the long-range Boeing B777-300ER. At Mach 0.839 (481 kts, $891 \mathrm{~km} / \mathrm{h})$, flight level FL300, temperature $-59{ }^{\circ} \mathrm{C}$ and at 513,400 lb (232.9 t) weight, the B777-300ER burns 17,300 lb (7.8 t) of fuel per hour [53] was chosen. To calculate fuel burn for aircraft using Dubins or 3HC trajectory, we used the Formula (55). In such a way, the total fuel burned per a certain time unit (Tables 3 and 4) was calculated.

$$
\text { Fuel burn (time) }=\frac{\text { fuel burn }[\mathrm{kg}]}{1 \text { hour }} \text {. flight time }
$$

Table 3. Fuel burn expressed by the flight time ( $35^{\circ}$ case).

\begin{tabular}{ccc}
\hline & Dubins & 3HC \\
\hline Time $[\mathrm{s}]$ & 355.22 & 356.78 \\
Fuel burn $[\mathrm{kg}]$ & 769.6 & 773 \\
\hline
\end{tabular}

Table 4. Fuel burn expressed by the flight time $\left(90^{\circ}\right.$ case).

\begin{tabular}{ccc}
\hline & Dubins & 3HC \\
\hline Time $[\mathrm{s}]$ & 387.82 & 331.54 \\
Fuel burn $[\mathrm{kg}]$ & 840.3 & 718.34 \\
\hline
\end{tabular}


As the amount of fuel burn depends on the length and duration of the flight, therefore, while comparing the conflict resolution methods based on the Dubins trajectory and $3 \mathrm{HC}$ (when the angle (of both trajectories) at the starting point of the simulation is $35^{\circ}$ ), very similar results with a minimal advantage of the Dubins method are calculated.

As the amount of fuel burn depends on the length and duration of the flight, therefore, when comparing the conflict resolution methods based on the Dubins trajectory and 3HC (when the angle (for both trajectories) at the starting point of the simulation is $90^{\circ}$ ), the advantage of the 3HC method against the Dubins method, which can be explained by the facts described above, i.e., the smaller radius $r_{O_{S}}$, is evident.

\section{Conclusions}

The aim of the paper was to compare two aircraft conflict resolution methods when the angle (for both trajectories) at the starting point of the simulation is $35^{\circ}$ and $90^{\circ}$, respectively.

The analyzes revealed that while the angle (for both trajectories) at the starting point of the simulation is $35^{\circ}$, in the case of the Dubins, the total trajectory length is $49.33 \mathrm{~nm}$, while for the $3 \mathrm{HC}$ case, it is $49.55 \mathrm{~nm}$. Thus, the difference in total trajectory length is $0.22 \mathrm{~nm}$, which results in a time difference of $\mathrm{t}=1.56 \mathrm{~s}$, and this, in turn, results in smaller fuel consumption of $3.4 \mathrm{~kg}$ for the Dubins case. Thus, it can be stated that for such a situation, the Dubins method is slightly more effective. Meanwhile, when the angle (for both trajectories) at the starting point of the simulation is $90^{\circ}$, in the case of the Dubins total trajectory, length is $53.86 \mathrm{~nm}$, while for the $3 \mathrm{HC}$ case, it is $46.05 \mathrm{~nm}$. Thus, the difference in total trajectory length is $7.81 \mathrm{~nm}$, which results in a time difference of $t=56.28 \mathrm{~s}$, and this, in turn, results in smaller fuel consumption of $122 \mathrm{~kg}$ for the $3 \mathrm{HC}$ case. Consequently, it can be stated that for such a situation, the $3 \mathrm{HC}$ method is much more effective.

For future research, the conflict resolution effectiveness methods could be extended by changing not only the radius $r_{O_{S}}$, but the radius $r_{O_{1}}$, assuring flight centrifugal acceleration is within acceptable limits. In addition, the third aircraft could be taken into consideration as well. Moreover, due regard could be allocated to different aircraft speeds and such uncertainties as wind angle and speed, navigation/positioning errors, etc., and their impact on the effectiveness of the analyzed aircraft conflict resolution concepts.

Author Contributions: Conceptualization, M.B., V.R. and J.S.; methodology, A.D., M.B. and J.S.; software, M.B., A.D. and J.S.; validation, M.B., A.D. and J.S.; formal analysis, A.D.; investigation, M.B., A.D. and J.S.; resources, M.B., A.D. and J.S.; data curation, M.B., A.D., V.R. and J.S.; writing-original draft preparation, A.D. and J.S.; writing-A.D., V.R. and J.S.; visualization, A.D. and V.R.; supervision, V.R., M.B. and J.S.; project administration, A.D.; funding acquisition, A.D. and V.R. All authors have read and agreed to the published version of the manuscript.

Funding: This research received no external funding. The APC was funded by VILNIUSTECH university and Antanas Gustaitis Aviation Institute.

Institutional Review Board Statement: Not applicable.

Informed Consent Statement: Not applicable.

Conflicts of Interest: The authors declare no conflict of interest.

\section{Appendix A}

Shape functions $N_{i}(\xi)$ and vectors $\boldsymbol{R}(\xi)=\sum_{i=1}^{5} N_{i}(\xi) \boldsymbol{R}_{P_{i}}$ for different values of parameter $\xi$, i.e., $0 \leq \xi \leq 1$ are given with the following formulas in Table A1. 
Table A1. Formulas of shape functions and vectors for different parameters $\xi$.

\begin{tabular}{|c|c|c|}
\hline Parameters & Shape Functions & Vectors \\
\hline$i=1, \xi=0$ & $N_{1}(\xi)=\frac{(\xi-\xi, 2)(\xi-\xi 3)(\xi-\xi 4)(\xi-\xi 5)}{((\xi \mathrm{i}-\xi 2)(\xi \mathrm{i}-\xi, 3)(\xi \mathrm{i}-\xi 4)(\xi \mathrm{i}-\xi 5))}$ & $\begin{array}{l}\boldsymbol{R}_{P_{1}}=\boldsymbol{R}_{O_{S}}-r_{O_{S}} \boldsymbol{e}_{1, O_{s}} \\
\text { Locally } \boldsymbol{R}_{P_{1}}^{\mathrm{T}}=[0,0,0]\end{array}$ \\
\hline$i=2, \xi=0.25$ & $N_{2}(\xi)=\frac{(\xi-\xi 1)(\xi-\xi 3)(\xi-\xi 4)(\xi-\xi 5)}{((\xi \mathrm{k}-\xi, 1)(\xi \mathrm{k}-\xi, 3)(\xi \mathrm{k}-\xi 4)(\xi \mathrm{k}-\xi 5))}$ & $\begin{array}{c}\boldsymbol{R}_{P_{2}}= \\
\boldsymbol{R}_{O_{S}}-\frac{1}{2} r_{O_{S}} \boldsymbol{e}_{1, O_{s}}+\frac{\sqrt{3}}{2} r_{O_{S}} \boldsymbol{e}_{1, O_{1}} \\
\text { Locally } \boldsymbol{R}_{P_{2}}^{\mathrm{T}}=[0.5 R, \sqrt{0.75 R}, 0]\end{array}$ \\
\hline$i=3, \xi=0.5$ & $N_{3}(\xi)=\frac{(\xi-\xi 1)(\xi-\xi 2)(\xi-\xi 4)(\xi-\xi 5)}{((\xi \mathrm{k}-\xi 1)(\xi \mathrm{k}-\xi 2)(\xi \mathrm{k}-\xi 4)(\xi \mathrm{k}-\xi 5))}$ & $\begin{array}{l}\boldsymbol{R}_{P_{3}}=\boldsymbol{R}_{O_{S}}+r_{O_{S}} \boldsymbol{e}_{1, O_{1}} \\
\text { Locally } \boldsymbol{R}_{P_{3}}^{\mathrm{T}}=[R, R, 0]\end{array}$ \\
\hline$i=4, \xi=0.75$ & $N_{4}(\xi)=\frac{(\xi-\xi 1)(\xi-\xi 2)(\xi-\xi 3)(\xi-\xi 5)}{((\xi, \mathrm{k}-\xi, 1)(\xi \mathrm{k}-\xi, 2)(\xi \mathrm{k}-\xi 3)(\xi \mathrm{k}-\xi, 5))}$ & $\begin{array}{c}\boldsymbol{R}_{P_{4}}= \\
\boldsymbol{R}_{O_{S}}+\frac{1}{2} r_{O_{S}} \boldsymbol{e}_{1, O_{s}}+\frac{\sqrt{3}}{2} r_{O_{S}} \boldsymbol{e}_{1, O_{1}} \\
\text { Locally } \boldsymbol{R}_{P_{4}}^{\mathrm{T}}=[1.5 R, \sqrt{0.75 R}, 0]\end{array}$ \\
\hline$i=5, \xi=1$ & $N_{5}(\xi)=\frac{(\xi-\xi 1)(\xi-\xi 2)(\xi-\xi 3)(\xi-\xi 4)}{\left((\xi, k-\xi 1)\left(\xi \mathrm{k}-\xi_{2}\right)\left(\xi \mathrm{k}-\xi_{3}\right)\left(\xi \mathrm{k}-\xi_{4}\right)\right)}$ & $\begin{array}{l}\boldsymbol{R}_{P_{5}}=\boldsymbol{R}_{O_{S}}+r_{O_{S}} \boldsymbol{e}_{1, O_{s}} \\
\text { Locally } \boldsymbol{R}_{P_{5}}^{\mathrm{T}}=[2 R, 0,0]\end{array}$ \\
\hline
\end{tabular}

\section{References}

1. ICAO. Procedures for Air Navigation Services-Rules of the Air and Air Traffic Services. DOC 4444-RAC/501; International Civil Aviation Organisation: Montreal, QC, Canada, 2016.

2. Coletsos, J.; Ntakolia, C. Air traffic management and energy efficiency: The free flight concept. Energy Syst. 2015, 8, 709-726. [CrossRef]

3. Xue, D.; Liu, Z.; Wang, B.; Yang, J. Impacts of COVID-19 on aircraft usage and fuel consumption: A case study on four Chinese international airports. J. Air Transp. Manag. 2021, 95, 102106. [CrossRef]

4. EUROCONTROL. Five-Year Forecast 2020-2024 European Flight Movements and Service Units Three Scenarios for Recovery from COVID-19 (STATFOR). 2020. Available online: https:/ /www.eurocontrol.int/sites/default/files/2020-11/eurocontrol-five-yearforecast-europe-2020-2024.pdf (accessed on 1 December 2021).

5. EUROCONTROL. Impact of COVID-19 on European Aviation in 2020 and Outlook 2021. 2021. Available online: https://www. eurocontrol.int/publication/what-covid19-did-european-aviation-2020-outlook-2021 (accessed on 22 January 2022).

6. Kondroška, V.; Stankūnas, J. Development of Lithuanian airspace structure/Lietuvos oro erdvès struktūros tobulinimas. Aviation 2012, 16, 124-129. [CrossRef]

7. Renner, P.; Rohacs, D.; Papp, G.; Kling, F. The Effects of the Introduction of Free Route (HUFRA, Hungarian Free Route Air-space) in the Hungarian Airspace. In Proceedings of the Eighth SESAR Innovation Days, Salzburg, Austria, 3-7 December 2018.

8. PBN Manual. Available online: https://pbnportal.eu/epbn/home/home.html (accessed on 1 January 2022).

9. Kraus, J. Free Route Airspace (FRA) in Europe; Czech Technical University; Faculty of Transportation; Department of Air Transportation: Prague, Czech, 2011.

10. Free Route Airspace (FRA). Concept of Operations. 2020. Available online: https://www.icao.int/MID/Documents/2018 / ACAC-ICAO\%20Civ-Mil\%20WS/13-\%20Session\%202.2-1.pdf (accessed on 6 January 2021).

11. Bicchi, A.; Marigo, A.; Pappas, G.J.; Pardini, M.; Parlangeli, G.; Tomlin, C.J.; Sastry, S.S. Decentralized Air Traffic Management Systems: Performance and Fault Tolerance. In Proceedings of the IFAC Workshop on Motion Control (MC'98), Grenoble, France, 21-23 September 1998; Volume 31, pp. 259-264.

12. Single European Sky Air Traffic Management Research Joint Undertaking (SESAR JU). European Air Traffic Management Master Plan. 2012. Available online: https:/ / www.atmmasterplan.eu (accessed on 14 November 2021).

13. Ntakolia, C.; Caceres, H.; Coletsos, J. A dynamic integer programming approach for free flight air traffic management (ATM) scenario with 4D-trajectories and energy efficiency aspects. Optim. Lett. 2020, 14, 1659-1680. [CrossRef]

14. Pallottino, L.; Feron, E.; Bicchi, A. Conflict resolution problems for air traffic management systems solved with mixed integer programming. IEEE Trans. Intell. Transp. Syst. 2002, 3, 3-11. [CrossRef]

15. Burghouwt, G.; Lieshout, R.; Boonekamp, T.; van Spijker, V. Economic Benefits of European Airspace Modernization; IATA: Montreal, QC, Canada, 2016.

16. European Union Aviation Safety Agency. Air Traffic Management and Operations. Available online: https://www.easa.europa. eu/eaer/topics/air-traffic-management-and-operations (accessed on 20 November 2021).

17. Pavlova, S.; Zadorozhnia, A. Analysis of free route airspace and performance-based navigation implementation in the European air navigation system. Proc. Natl. Aviat. Univ. 2014, 61, 28-35. [CrossRef] 
18. Antulov-Fantulin, B.; Rogošić, T.; Juričić, B.; Andraši, P. Air Traffic Controller Assessment of the Free Route Airspace Implementation within Zagreb Area Control Center. 2018. Available online: https:/ / www.semanticscholar.org/paper/Air-TrafficController-Assessment-of-the-Free-Route-Antulov-Fantulin-Rogošić/0e77879cc3e41598436a5930360d236b608fa020 (accessed on 1 November 2021).

19. Yang, L.C.; Kuchar, J.K. Prototype Conflict Alerting System for Free Flight. J. Guid. Control Dyn. 1997, 20, 768-773. [CrossRef]

20. Kharcenko, V.; Vasyliev, D.; Vasyliev, V. Synthesis of conflict-free aircraft flight trajectories using multi-criteria dynamic programming. Aviation 2017, 21, 35-41. [CrossRef]

21. Ruigrok, R.; van Gent, R.; Hoekstra, J. The Transition Towards Free Flight: A Human Factors Evaluation of Mixed Equipage, Integrated Air-Ground, Free Flight ATM Scenarios. In SAE Technical Paper Series; SAE International: New York, NY, USA, 1999. [CrossRef]

22. European Union Aviation Safety Agency. Commission Regulation (EU) 2014/716. Available online: https://easa.europa.eu (accessed on 15 November 2021).

23. Gaxiola, C.A.N.; Barrado, C.; Royo, P.; Pastor, E. Assessment of the North European free route airspace deployment. J. Air Transp. Manag. 2018, 73, 113-119. [CrossRef]

24. Figueres, C.; Le Quéré, C.; Mahindra, A.; Bäte, O.; Whiteman, G.; Peters, G.; Guan, D. Emissions are still rising: Ramp up the cuts. Nature 2018, 564, 27-30. [CrossRef] [PubMed]

25. Dudoit, A.; Skorupski, J. A Simulation-Based Approach for the Conflict Resolution Method Optimization in a Distributed Air Traffic Control System. In Research Methods and Solutions to Current Transport Problems; Springer: Cham, Switzerland, 2019; pp. 104-114.

26. Krozel, J.; Peters, M.E.; Hunter, G. Conflict Detection and Resolution for Future Air Transportation Management; Seagull Technology: Los Gatos, CA, USA, 1997.

27. Krozel, J.; Peters, M. Conflict Detection and Resolution for Free Flight. Air Traffic Control Q. 1997, 5, 181-212. [CrossRef]

28. Tang, J. Conflict Detection and Resolution for Civil Aviation: A Literature Survey. IEEE Aerosp. Electron. Syst. Mag. 2019, 34, 20-35. [CrossRef]

29. Kuchar, J.; Yang, L. A review of conflict detection and resolution modeling methods. IEEE Trans. Intell. Transp. Syst. 2000, 1, 179-189. [CrossRef]

30. Kikutis, R.; Stankūnas, J.; Rudinskas, D.; Masiulionis, T. Adaptation of Dubins Paths for UAV Ground Obstacle Avoidance When Using a Low Cost On-Board GNSS Sensor. Sensors 2017, 17, 2223. [CrossRef]

31. Enea, G.; Porretta, M. A comparison of 4D-trajectory operations envisioned for NEXTGEN and SESAR, some preliminary findings. In Proceedings of the 28th International Congress of Aeronautical Sciences ICAS 2012, Brisbane, Australia, 23-28 September 2012.

32. FAA/EUROCONTROL. Comparison of Air Traffic Management-Related Operational Performance U.S./EUROPE 2017; 2019. Available online: https:/ /www.faa.gov/air_traffic/publications/media/us_eu_comparison_2017.pdf (accessed on 22 January 2021).

33. Hoy, P.D.; The Boeing Company. Lateral Avoidance Maneuver Solver. U.S. Patent Application No. 9,262,933, 16 February 2016.

34. Hoekstra, J.M.; Gent, R.N.H.W.; Ruigrok, R.C.J. Designing for Safety: The 'Free Flight' Air Traffic Management Concept, NLR. In Proceedings of the 3rd Workshop on Human Error, Safety, and System Development, Liege, Belgium, 7-8 June 1999.

35. Wee, H.J.; Lye, S.W.; Pinheiro, J.-P. An integrated highly synchronous, high resolution, real-time eye tracking system for dynamic flight movement. Adv. Eng. Inform. 2019, 41, 100919. [CrossRef]

36. Xue, D.; Hsu, L.-T.; Wu, C.-L.; Lee, C.-H.; Ng, K.K. Cooperative surveillance systems and digital-technology enabler for a real-time standard terminal arrival schedule displacement. Adv. Eng. Inform. 2021, 50, 101402. [CrossRef]

37. Warren, A. Medium term conflict detection for free routing: Operational concepts and requirements analysis. In Proceedings of the 16th DASC. AIAA/IEEE Digital Avionics Systems Conference. Reflections to the Future. Proceedings, Irvine, CA, USA, 30 October 2018. [CrossRef]

38. EUROCONTROL. Safety Nets. A Guide for Ensuring Effectiveness. Brussels. 2017. Available online: https://skybrary.aero/ bookshelf/books/2761.pdf (accessed on 5 October 2021).

39. Skorupski, J. Metody wymiarowania bezpieczeństwa ruchu Lotniczego. In Prace Naukowe Politechniki Warszawskiej-Transport; Warsaw University of Technology Publishers: Warsaw, Poland, 2008.

40. Zhang, X.; Mahadevan, S. Aircraft re-routing optimization and performance assessment under uncertainty. Decis. Support Syst. 2017, 96, 67-82. [CrossRef]

41. Gariel, M.; Feron, E. Graceful Degradation of Air Traffic Operations: Airspace Sensitivity to Degraded Surveillance Systems. Proc. IEEE 2008, 96, 2028-2039. [CrossRef]

42. Ali, B.S.; Ochieng, W.Y.; Zainudin, R. An analysis and model for Automatic Dependent Surveillance Broadcast (ADS-B) continuity. GPS Solut. 2017, 21, 1841-1854. [CrossRef]

43. Air Transport Action Group. Revolutionizing Air Traffic Management; Air Transport Action Group: Geneva, Switzerland, 2012; pp. $1-32$.

44. Park, J.; Han, J.; Kim, J.; Son, N.-S. Probabilistic quantification of ship collision risk considering trajectory uncertainties. IFAC-Pap. 2016, 49, 109-114. [CrossRef]

45. Skorupski, J. About the Need of a New Look at Safety as a Goal and Constraint in Air Traffic Management. Procedia Eng. 2017, 187, 117-123. [CrossRef] 
46. Weisstein, E.W. Line-Line Intersection. 2019. Available online: https://mathworld.wolfram.com/Line-LineIntersection.html (accessed on 16 March 2021).

47. Dubins, L.E. On Curves of Minimal Length with a Constraint on Average Curvature, and with Prescribed Initial and Terminal Positions and Tangents. Am. J. Math. 1957, 79, 497. [CrossRef]

48. Reeds, J.A.; Shepp, L.A. Optimal paths for a car that goes both forwards and backwards. Pac. J. Math. 1990, 145, 367-393. [CrossRef]

49. ICAO. Procedures for Air Navigation Services-Air Traffic Management, DOC. 4444; International Civil Aviation Organisation: Montreal, QC, Canada, 2007.

50. Yanto, J.; Liem, R.P. Efficient fast approximation for aircraft fuel consumption for decision-Making and policy analysis. In Modeling and Simulation for the Air Transportation System; AIAA: Denver, CO, USA, 2017. [CrossRef]

51. Xue, D.; Ng, K.K.H.; Hsu, L.-T. Multi-Objective Flight Altitude Decision Considering Contrails, Fuel Consumption and Flight Time. Sustainability 2020, 12, 6253. [CrossRef]

52. Dudoit, A.; Stankūnas, J. The comparison of the en-route horizontal flight trajectory components. Moksl. Liet. Ateitis Sci. Future Lith. 2016, 7, 557-582. [CrossRef]

53. Casanova, A.M.; Leeuwen, B.; Capelle, C.; Finn, S.; Guo, S. An Overview of Commercial Aircraft 2018-2019. 2017. Available online: www.dvbbank.com/ /media/Files/D/Dvb-Bank-Corp/aviation/dvb-overview-of-commercial-aircraft-2017-2018.pdf (accessed on 14 January 2021). 